\title{
Narrativas sobre o início das práticas fonoaudiológicas na cidade de Salvador, Bahia, Brasil
}

\author{
Narratives on the beginning of speech therapy services in \\ the city of Salvador, Bahia, Brazil
}

\author{
Rina Tereza D'Angelo Nunes \\ Fonoaudióloga. Mestrado em Fonoaudiologia. Professora Assis- \\ tente do Curso de Fonoaudiologia da Universidade do Estado da \\ Bahia - UNEB. \\ Endereço: Rua Engenheiro Ademar Fontes, 254, ap. 60I, Pituba, \\ CEP 41810-710, Salvador, Bahia, Brasil. \\ E-mail: rinadangeloळterra.com.br

\section{Suzana Magalhães Maia} \\ Psicanalista. Doutorado em Linguistica. Professora-Titular da \\ Pontifícia Universidade Católica de São Paulo - PUC - SP. \\ Endereço: Rua Michigan, 322, Cidade das Monções, CEP 04566-000, \\ São Paulo, SP, Brasil. \\ E-mail: suzana-maiaœuol.com.br
}

\section{Resumo}

A implantação dos cursos de fonoaudiologia no Estado da Bahia data de 1999. Ainda que a formação acadêmica seja recente, na cidade de Salvador a sua história é mais longínqua e em muitos aspectos se articula com as preocupações que vêm marcando o campo. Para conhecermos esse trajeto histórico, este artigo apresenta narrativas de fonoaudiólogas precursoras na capital baiana, buscando nas suas experiências um saber que configure fonte para compreensão do passado e do presente e projeção do futuro. A colheita das narrativas foi realizada na perspectiva da metodologia da história oral. As vozes das narradoras emolduram a fonoaudiologia em Salvador como acontecimento singular e, ao mesmo tempo, característico da forma como a área foi se constituindo no Brasil, sendo destacados aspectos como: prevalência de um trabalho fonoaudiológico privatista como resultado de políticas públicas equivocadas; reconhecimento por parte dos pacientes como forma primordial de divulgação da área; contribuição local para sua institucionalização; primeiras práticas relacionadas à educação de pessoas surdas e com deficiência mental. Contam também sobre uma clínica que não quer prescrever, em que os envolvidos trabalham juntos vivendo a experiência do encontro. Uma clínica que reconhece o que de singular se organizou em cada pessoa para além do registro do vivido, do psíquico, voltado para o sentimento, para a reciprocidade e a aspiração de todo humano: estar incluído, ser cuidado.

Palavras-chave: Fonoaudiologia; História; Narrativas; História oral. 


\section{Abstract}

The introduction of courses in Speech Therapy (ST) in the State of Bahia dates from 1999. Although the courses are recent, the history of this practice in Salvador is more distant and in many ways articulates the concerns that have marked the ST. In order to present this history, this article presents narratives of the first speech therapists in the city of Salvador, seeking in their experiences a source for understanding the profession's past and present, as well as its future projections. The gathering of narratives was made using Oral History methodology, that is, the story is told by its own actors. Narrators' voices frame ST in Salvador as a unique event which is, at the same time, characteristic of how the area has been constituted in Brazil. They distinguish features such as the prevalence of private speech therapy practices as a result of misguided public policies; the recognition by patients as the primary form of publicity for the professionals and local contribution to the institutionalization. Interviewees spoke about the first practices related to the education of deaf and mentally disabled patients, and also about an experience of a holistic clinic, which did not want to prescribe, where people worked together, living the experience of the encounter: a clinic that recognized that singularity was organized in each person beyond the record of the lived experience, open to the sentiment, to reciprocity for all human aspiration: to be included, to be taken care of.

Keywords: Speech Therapy; History; Personal Narratives; Oral History.

\section{Introdução}

Podemos colher enorme quantidade de informações factuais, mas o que importa é delas fazer emergir uma visão de mundo (Bosi, 2004, p. 19).

É crescente o número de trabalhos cujo objeto de investigação é o conhecimento histórico. Isso pode ser facilmente identificado com levantamento em bancos de dados de várias áreas do conhecimento. São muitas histórias: de pessoas, profissões, empresas, lugares, acontecimentos. Diante disso, Bosi questiona se o movimento de recuperação da memória nas ciências humanas é apenas uma "moda acadêmica" ou tem origem mais profunda, como necessidade de enraizamento. A autora conclui: "Do vínculo com o passado que se extrai a força para formação de identidade. [...] Fontes de outras épocas repropõem questões sobre o presente" (Bosi, 2004, p. 16).

A história diz de nossa condição humana, nos remete à origem e nos leva a refletir sobre a vida presente. Quando fazemos história, estamos contando uma experiência, transmitindo aquilo que sabemos sobre os acontecimentos, afetos e sofrimentos que marcaram um viver, um "saber". É movimento que cria maneiras diversas de pensar e ver o vivido, abrindo perspectivas.

Histórias da fonoaudiologia já descritas mostram particularidades dos seus lugares de acontecimento e uma diversidade de intenções e argumentações, tais como: compreensão da sua origem à luz do momento sociopolítico vigente (Figueredo Neto, 1988); afirmação do seu marco referencial institucional como origem que, ao colocá-la como uma profissão jovem (25/30 anos), trabalha no sentido de não enfrentamento dos conflitos e confrontos naturais que a habitam como prática social (Berberian, 1993); questionamento das dimensões técnicas e curativas que predominam no campo profissional (Silveira, 1996); dificuldades e conflitos no processo de constituição da fonoaudiologia por meio da caminhada de diversos atores (Danesi e Martinez, 2001); estudo da contraposição das origens do fazer fonoaudiológico entre Recife e São Paulo (Didier, 2001); as dificuldades de inserção na Amazônia devido ao isolamento geográfico, dificuldades de união da categoria e a desvalorização profissional 
pelo aumento da produtividade, marcada por serviços mal prestados a preços humilhantes (Kauffman, 2006); e a reafirmação do papel da Legião Brasileira de Assistência (LBA) na inclusão e desenvolvimento da profissão, em Minas Gerais (Aarão e col., 2011; Pereira e col., 2012).

A criação dos cursos de fonoaudiologia na Universidade Federal da Bahia (UFBA) e na Universidade do Estado da Bahia (UNEB) data de 1999. Há um equívoco recorrente ao associar-se o início das práticas fonoaudiológicas em Salvador a esta institucionalização e/ou à chegada de profissionais contratados pela LBA nos anos 1980 (Cardoso e Abreu, 2004; Aarão e col., 2011). Ainda que a formação acadêmica e a LBA tenham contribuído para o seu fortalecimento, a história da área em Salvador é mais longínqua e em muitos aspectos se articula com as preocupações que vêm marcando a fonoaudiologia.

Observando a necessidade de ampliar o conhecimento dos diferentes modos pelos quais a fonoaudiologia tem sido pensada e vivida, apresentamos aqui as narrativas de fonoaudiólogas precursoras da profissão na cidade de Salvador, Bahia. São experiências vividas, vozes que se tornam fonte para compreensão do presente e projeção do futuro.

\section{Percurso metodológico}

O caminho metodológico escolhido para a construção das histórias foi a metodologia da história oral (Meihy, 2005). Trata-se do registro da história de vida de indivíduos que testemunharam acontecimentos, conjunturas, instituições, modos de vida ou outros aspectos históricos contemporâneos - história viva, do tempo presente. Ao focalizar suas memórias pessoais, constroem então uma visão dinâmica da trajetória do grupo social ao qual pertencem. A utilização dessa metodologia data dos anos 1950, após a invenção do gravador, nos Estados Unidos, na Europa e no México, sendo praticada entre historiadores, antropólogos, cientistas políticos, sociólogos, pedagogos, teóricos da literatura, psicólogos e fonoaudiólogos, entre outros (Amado e Ferreira, 2001).

Nessa perspectiva, optar por história oral é trabalhar com a subjetividade e a linguagem que se constrói dentro de um processo histórico. Ela permite aproximar depoente e pesquisador, trazendo conhecimento, respeito mútuo e a possibilidade de acesso a uma pluralidade de memórias e perspectivas do passado, ultrapassando a descrição para compreender seus significados: "[...] O fundamento essencial da História Oral é estabelecer a relação entre identidade e memória - ou vice-versa [...]" (Meihy, 2006, p. 142).

Pelo fato de a fonoaudiologia constituir-se como profissão majoritariamente feminina (Pereira, 1999), as colaboradoras do estudo que deu origem a este artigo foram todas mulheres. São elas:

- Carmen das Graças Fernandes, entrevista marco zero, escolhida para iniciar a rede de colaboradoras pelo estreito contato com fonoaudiólogos que atuam em Salvador desde a sua chegada à cidade, em 1979, e pela constante militância profissional como membro da Associação Profissional dos Fonoaudiólogos do Estado da Bahia - Aprofeb.

- Elieth Leal D’Araujo (Lia Mara), fonoaudióloga, natural de Salvador, graduada em direção teatral em 1972 e professora aposentada da Escola de Arte Dramática da Universidade Federal da Bahia - UFBA. - Olga Lima Rodrigues Tanajura, fonoaudióloga pelo curso de terapia da palavra, ministrado pelas professoras Lucia Bentes e Ruth Pereira, no Rio de Janeiro em 1968; já cuidou de muitas gerações de baianos, sendo um nome reverenciado por todos.

- Sonia Veloso, fonoaudióloga, funcionária pública aposentada da Secretaria de Educação do Estado da Bahia, pioneira em Salvador no trabalho com audiologia e surdez.

- Leonora Bastos da Silva, fonoaudióloga pela Universidade Católica de Petrópolis (RJ), com início do exercício fonoaudiológico em Salvador em 1976, atualmente trabalha em saúde mental como funcionária da Prefeitura de Salvador e prestadora de serviço na Secretaria da Saúde do Estado da Bahia.

\section{Vozes das narradoras}

A construção singular da fonoaudiologia em Salvador traz aspectos comuns em relação ao percurso histórico da área no país. É, pois, recorrente a associação entre o aparecimento das primeiras práticas fonoaudiológicas e as ações/intervenções em saúde pública, que, estruturadas sob vários paradigmas 
históricos, estabeleceram os modelos e objetivos da atenção. A capital baiana também compartilhou desse momento. Destacamos, nas narrativas colhidas sobre a fonoaudiologia em Salvador, algumas experiências que se incluem nessa perspectiva, como, por exemplo, a presença do Peace Corps ${ }^{1}$, situado em momento histórico de "ajuda externa", de perfil voluntário aos programas sociais internos. (Azevedo, 1998).

Este trabalho fez com que "Irmão Dubois", o diretor do Instituto de Psicologia da Universidade Católica do Salvador me procurasse para trabalhar com problemas de linguagem e também para participar de um curso específico que seria oferecido por uma fonoaudióloga norte-americana, integrante dos Voluntários da Paz (Peace Corps/Corpos da Paz) chamada Carol Perry (Lia Mara).

Também como programas públicos de ação em saúde/educação, temos a atuação em práticas fonoaudiológicas de professoras no âmbito da Secretaria Estadual de Educação da Bahia ("professoras de Calafasia”).

Na Secretaria da Educação havia Aldina e Vandiva, que trabalhavam como logopedistas. [...] Eram professoras antigas da Secretaria da Educação que fizeram o curso do INES e atendiam crianças especiais e também aquelas que vinham pela queixa da escola... (Sonia Veloso)

No final dos anos 1970 e início dos anos 1980, fonoaudiólogos chegaram a Salvador para trabalhar em clínicas de reabilitação que mantinham convênio com a Fundação Legião Brasileira de Assistência Social (LBA)². Vejamos o que disseram as colaboradoras:

No início dos anos 1980, a Legião Brasileira de Assistência - LBA foi responsável pela chegada de vários profissionais a Salvador. Parece-me que, por determinação do governo, para se conveniar, toda clínica necessitava ter na equipe, entre outros profissionais, um fonoaudiólogo [...] em 1984, e já foi uma outra etapa. A LBA já não atuava muito, mas nem lembro como isto foi acontecendo [...] (Carmen Fernandes)

Em sua dissertação sobre gestão e política de assistência social no Brasil, Monfredini faz as seguintes considerações sobre a LBA:

A diversidade de atuação apesar de apresentar certa flexibilidade, tinha em sua marca a descontinuidade e a ausência de mecanismos de controle e de integração, favorecendo o uso político da instituição que acabou por desgastar sua imagem. Os traços centrais que reproduziram um perfil do órgão podem ser vistos por algumas características mais gerais de: i) grande flexibilidade nas formas de atuação; ii) descontinuidade dos programas; iii) ausência de mecanismos de controle, participação social, planejamento e avaliação; iv) desarticulação das ações; v) uso político da instituição e fonte permeável à corrupções e fraudes (Monfredini, 2003, p. 56).

É possível identificar nas narrativas as lutas empreendidas no cotidiano, por meio de um trabalho fonoaudiológico privatista; ou seja, é quase ausente a inserção no serviço público, sendo o acesso da população somente mediante pagamento. Temos, portanto, em Salvador, uma fonoaudiologia construída pela iniciativa privada, como resultado de políticas públicas que não primam pelo planejamento estratégico de longo prazo, que mudam ao sabor das conveniências.

Em 1957, [...] aceitei um convite [...] para trabalhar no Instituto Pestalozzi, que ela havia fundado em

\footnotetext{
1 Peace Corps (Corpos da Paz; Voluntários da Paz): agência governamental norte-americana criada pelo presidente John Kennedy no início do seu governo, com o objetivo de enviar voluntários ao então chamado Terceiro Mundo para trabalhar em projetos de assistência comunitária, especialmente nas áreas de educação, saúde e desenvolvimento agrícola.

2 A LBA foi a primeira instituição pública federal de assistência social no Brasil, criada em outubro de 1942, cuja presidência estava assegurada às primeiras-damas da República. Em 1946, redefiniu sua finalidade para a defesa da maternidade e da infância, tornando-se uma fundação em 1969. Após cinco anos (1974), foi incorporada ao Ministério da Previdência e Assistência Social (MPSA) e, em 9 de fevereiro de 1979, o Decreto-Lei 8.2.1979 aprovou seu estatuto, estabelecendo como objetivo principal a prestação de assistência social à população carente, mediante programas de desenvolvimento social e de atendimento às pessoas, independentemente da vinculação destas a outra entidade do SINPAS (Sistema Nacional de Previdência e Assistência Social). No primeiro governo de Fernando Henrique Cardoso (1995-1998), a LBA foi extinta e seu patrimônio foi repassado aos Estados e municípios, sendo a grande maioria dos técnicos encaminhada para as secretarias estaduais.
} 
Salvador. Algum tempo depois, para sua decepção e de todos os pais, o governador Antonio Balbino fechou o Instituto Pestalozzi, talvez por considerar que gastar com excepcionais não valia a pena. [...] Os pais das crianças tiveram que procurar escolas particulares... (Olga Tanajura)

A Educação precoce caminhava, mas as crianças não tinham como comprar aparelho e, quando conseguiam, não havia condições de fazer a manutenção. [...] O Centro de Educação Especial finalmente ficou pronto [...] e também salas para atendimento fonoaudiológico, porque buscávamos criar condições para que o fonoaudiólogo pudesse fazer parte do quadro de profissionais do Estado. [...] mas o Estado não assumiu esse compromisso e até hoje o fonoaudiólogo não está inserido neste quadro. [...] Eu fiquei muito desanimada com o grupo de estudo, porque trabalhávamos e nos dávamos conta de que nada seria aplicado na prática. No Estado é muito difícil trabalhar um projeto de longo prazo... (Sonia Veloso)

No Centro Terapêutico Municipal Dr. Álvaro Rubim de Pinho cheguei sem saber o que me esperava. Nunca havia trabalhado na área de saúde mental. Lá sou fonoaudióloga generalista, tenho que dar conta de uma grande demanda de pacientes. O que eu não posso atender, como dislexias, disfonias orgânicas etc., faço encaminhamento para outros serviços. $O$ problema é: para onde? (Leonora)

Com essa atuação privada, única possível nesse contexto de grande demanda da população e pouco compromisso dos órgãos públicos, as precursoras da fonoaudiologia em Salvador foram adquirindo experiência, investindo na formação e percebendo os efeitos desse trabalho, que era muito reconhecido pelos pacientes. Esse reconhecimento fez com que elas ganhassem confiança para divulgar a área:

Como fui obtendo alguns resultados, começaram a aparecer muitas crianças com problemas de fala e, então, aluguei uma sala para atender [...] Ao retornar deste curso de D. Lucia Bentes, no Rio de Janeiro, participei de programas de televisão, fiz palestras, reuniões com professores e também dentistas, porque, nesse curso, já haviam sido introduzidas noções mais específicas de motricidade oral... (Olga Tanajura)
[...] Falando da divulgação, as pessoas não conheciam o nosso trabalho, e os encaminhamentos eram feitos de modo vago. [...] Havia certa fragilidade nesses encaminhamentos. [...] Mas não demorou muito e nós conseguimos alguma estabilidade graças ao trabalho de arregaçar as mangas e ir pessoalmente conversar com os profissionais, as escolas, professores, diretores etc. Todas se esforçaram... (Carmen Fernandes)

É interessante observar os relatos entusiasmados e orgulhosos das lutas vencidas pelos pacientes, demonstrando uma cumplicidade /solidariedade com eles:

[...] Em 1975, [...] Dr. Hélio Lessa [...], Dr.Cortizo e Dr. Antonio Borja nos convidaram para fazer umas palestras no auditório da Ordem dos Advogados da Bahia (OAB). [...] Um paciente com laringectomia se ofereceu para falar do seu caso e foi ótimo. Ele falou muito bem e disse que eu tinha restituído não só a voz dele, mas também a vida [...] (Olga Tanajura)

Além do trabalho pontual de cada profissional em clínicas privadas, podemos destacar também um grande investimento paralelo no trabalho de institucionalização da área: reconhecimento da profissão, organização de classe em Salvador e persistência no objetivo de conseguir a formação de novos profissionais.

[...] Abigail Caracik, uma pessoa muito dinâmica, com um trabalho maravilhoso no Rio de Janeiro, que me sugeriu formar um grupo de fonoaudiólogos na Bahia... (Olga Tanajura)

[...] Nesta época, trabalhamos no reconhecimento da profissão junto ao Congresso Nacional e o MIEF - Movimento Interestadual das Entidades Fonoaudiológicas. Tenho muito orgulho de ter participado destas reuniões em Salvador e em outros Estados, na luta pela criação do Conselho Federal de Fonoaudiologia e reconhecimento da profissão junto ao Congresso Nacional. [...] Na administração da prefeita Lídice da Mata tivemos uma reunião com seu Secretário da Saúde. [...] Ele nos pediu um levantamento da necessidade de atuação do fonoaudiólogo em todos os postos de saúde da cidade de Salvador. Foi feito um mutirão com os colegas fonoaudiólogos. [...] Recebemos a visita da professora Maria Augusta Dantas do Nascimento, do Instituto 
de Ciências da Saúde da Universidade Federal da Bahia, falando da possibilidade de criação do Curso de Fonoaudiologia... (Leonora)

Em relação a outras histórias já relatadas sobre a fonoaudiologia no Brasil e as apresentadas pelas colaboradoras em Salvador, podemos destacar em comum uma matriz formadora que diz respeito ao investimento na educação de pessoas surdas e com deficiência mental, em âmbito geral nas ações ligadas ao poder público e, no particular, na mobilização de pais interessados em oferecer oportunidades aos seus filhos.

Nesse contexto, é interessante referir aspectos da história da educação do surdo no Brasil, tratados na tese de doutorado de Leite Soares. A autora refaz o percurso histórico do Instituto Nacional de Educação de Surdos (INES), no Rio de Janeiro, desde a sua fundação, no final do século XIX, até o final da administração da professora Ana Rimoli, em 1961, na intenção de compreender a incorporação do oralismo como método pedagógico na educação do surdo na década de 1950 (Soares, 1996).

Entre os aspectos relevantes tratados, destacamos aqui a priorização da oralização (preparar para a escola) em detrimento da escolarização e os seus desdobramentos: foco em técnicas para trabalhar a fala, com perfil individualizado, abordagem terapêutica que se aproxima do enquadre da fonoaudiologia, e a preparação de professores de vários Estados do Brasil, incluindo a Bahia, por meio de cursos oferecidos pelo governo, para a reprodução desse modelo:

Minha história na fonoaudiologia começa na Secretaria de Educação do Estado da Bahia. [...] Eu era pedagoga, mas sem nenhuma formação especial. Em 1972, fui fazer um curso de um ano no Instituto Nacional de Educação de Surdos o que despertou meu interesse sobre a surdez... (Sonia Veloso)

Assim como relatado em São Paulo (AACD - Associação de Assistência a Criança Deficiente) e Rio de Janeiro (Sociedade Pestalozzi), Salvador também traz na origem das suas primeiras práticas fonoaudiológicas o trabalho com pessoas portadoras de deficiência mental, por meio das iniciativas da Sociedade Pestalozzi da Bahia, Instituto Bahia de Reabilitação (IBR), Clínica de Paralisia Cerebral Dr. Pinto Duarte, APAE (Associação de Pais e Amigos dos
Excepcionais) e outras instituições credenciadas pela LBA.

[...] Eu já tinha alunos particulares com deficiência mental e achava que eles necessitavam falar melhor, mas não sabia como ajudá-los. Encontrei [...] o livro Defectos de la diccion infantil, de Tobias Corredeira Sanches. [...] Com ele fui trabalhando a fala das crianças... (Olga Tanajura)

Cheguei a Salvador em maio de 1979, [...] para trabalhar com crianças com paralisia cerebral e atraso de linguagem... (Carmen Fernandes)

Por fim, nessas cinco histórias precursoras é marcante o trabalho de reflexão sobre o fazer clínico na fonoaudiologia. As narrativas tocam em dimensões que encontram ressonância em proposições discutidas pelo psicanalista Gilberto Safra, quando se refere à clínica na contemporaneidade e à concepção de homem constituído historicamente, único e múltiplo, que se singulariza pela presença de outros do passado, do presente e dos que virão, das coisas e da natureza (Safra, 2004). Como clínicos, nos colocarmos humanos entre humanos:

Ao voltarmos para a situação clínica, veremos que ela se caracteriza pelo cuidado que estabelece as condições necessárias ao acontecer humano. Esses são fatos que me levam a afirmar que a clínica é essencialmente ética e a ética é clínica! Nessa perspectiva, cai por terra toda concepção que busca definir a situação clínica a partir de procedimentos técnicos. A técnica assim compreendida joga o paciente em direção ao conceituável, roubando-lhe o indizível e os mistérios do seu ser. Este é o homem-coisa e não mais ser, não mais presença (Safra, 2004, p. 27). [grifos nossos]

Nas vozes das narradoras há uma visão de mundo que se expressa em valores essenciais para o acontecer humano, como a gratidão, o entusiasmo, o respeito e o acolhimento ao jeito de ser do outro, a responsabilidade social, a solidariedade, o compromisso com a pessoa antes do compromisso com "técnicas", "escolas", "correntes teóricas" etc.

É possível identificar nas narrativas situações exemplares, conselhos tecidos na experiência - são bons momentos de reflexão para a fonoaudiologia. Vamos a eles: 
- A clínica é dialética e paciente e terapeuta se constituem mutuamente. 0 investimento do terapeuta pelo conhecimento que surge dessas demandas chama-se compromisso. $\mathrm{O}$ estar mutuamente afetado implica acolhimento em comunidade.

Fui cuidando de disfonia e busquei aprender mais coisa. Fiz muitos cursos para trabalhar o corpo [...] Estudei expressão corporal e karatê [...]Estudava o que vinha na cabeça, o que me parecia relacionado com a fala, embora aparentemente não tivesse. [...] Já tinha feito também yoga, mas achei que o tai chi chuan juntava a yoga. [...] Fiz o curso de três anos do "Trauma tem cura", com Peter Levine. [...] Isto tudo era uma procura minha para, em menos tempo possível, respeitando o indivíduo, fazer com que ele se libertasse da escravidão, da gaiola que vivia, de se sentir preso na comunicação com o outro... [grifos nossos] (Lia Mara)

o conhecimento fonoaudiológico que você oferece aos pacientes através do seu trabalho, mesmo não se misturando nas relações, tem repercussão pessoal, no destino deles. Por exemplo, vocêfaz um trabalho com o surdo, ele se identifica, melhora, começa a falar e obtém suporte necessário para suas relações interpessoais, tudo isto através da comunicação que foi desenvolvida por este trabalho. Quando ele começa também a caminhar com os próprios pés, há uma reciprocidade, não é uma situação unilateral. Não é assim: eu tenho todo o conhecimento e o outro não tem nada para me dar. Eu sempre, de alguma maneira, estou aprendendo com a outra pessoa, enfim a gente trata de humano mesmo. Sei que eu tenho a obrigação de ter conhecimento profissional, de me especializar, de oferecer suporte técnico, mas passa tudo pelo humano, pela possibilidade de crescimento conjunto... Igrifos nossos] (Carmen Fernandes)

- A relação terapêutica é complexa, porque as pessoas são complexas e as possibilidades de trabalho não podem se reduzir à aplicação de técnicas.

Conhecer-se, conhecer sua voz e com isso poder fazer o personagem que quiser. Você não impõe voz, você administra e aumenta o repertório [...] Não adianta dar adestramento para o falante se você não trabalhar a mente da pessoa para se libertar e gostar de si mesma. Tenho a impressão de que podemos, neste teatro da vida, ter uma performance aceitável, mas eu prefiro que seja uma verdade aceitável, porque de performance já estamos saturados... [grifos nossos] (Lia Mara)

[...] Eu lhe disse que antes de atendê-lo iria ao Rio de Janeiro procurar uma supervisão. [...] Foi um caso extraordinário, porque esse homem estava perdido completamente, estava sem fala, tinha sido abandonado pela mulher e chorava muito. Consegui que ele falasse o / pá/, e ele sentiu uma emoção extraordinária [...], nos convidaram para fazer umas palestras no auditório da Ordem dos Advogados da Bahia (OAB) e este paciente com laringectomia se ofereceu para falar do seu caso [...]Disse que eu tinha restituído não só a voz dele, mas também a vida [...]Anos depois, numa reunião da APROFEB, encontrei uma psicóloga que tinha ido a este evento e ela me falou da emoção extraordinária que tinha sentido ao assistir este depoimento... Igrifos nossos] (Olga Tanajura)

- Uma técnica, uma teoria, um conceito não podem se aplicar ao humano de forma universal; podem, quando muito, iluminar uma das infinitas faces que todos os dias serão renovadas pela conspiração de passado, presente e futuro, no jogo eterno e misterioso da criatividade humana.

A voz pra mim é a alma da pessoa, é o alto-falante. Penso que quando a pessoa tranca a garganta é porque ela já engoliu muito sapo. Acredito que temos que trabalhar tocando a pessoa por dentro, não só querendo a performance de uma voz impostada (miniminiminimi), porque quando ela estiver numa situação fronteiriça voltaria tudo. [...] Fui convidada para ministrar aulas de respiração na Escola de Surdos Wilson Lins. Logo ao chegar me ocorreu que não estava trabalhando com surdos, mas com pessoas, crianças. Pensava: vou trabalhar com a voz ou com a pessoa? [grifos nossos] (Lia Mara)

[...] Tive muitos pacientes que desenvolveram e outros que não conseguiram. [...] Tive um paciente que foi e é, até hoje, um caso extraordinário. [...] Ele tinha uma perda auditiva profunda e uma comunicação maravilhosa. [...] Foi um caso muito bom, porque ele também era muito inteligente e a família tinha 
todas as condições possíveis, embora outros com a mesma perda auditiva e as mesmas condições não iam adiante... [grifos nossos] (Sonia Veloso)

- O clínico então é um aprendiz-cuidador, aberto a todo o conhecimento que possa ajudá-lo a cuidar, na interdisciplinaridade da ciência, nas diversas manifestações da arte, nas religiões, na cultura etc.

[...] Acho interessante trabalharem com a infância, porque é aí que começa a inibição de fala. [...] Hoje é necessário preparar o pessoal que está chegando, na creche se possivel. [...] Quando a criança começa a engatinhar, andar e cai, ninguém acha ruim; agora, quando começa a falar e gagueja, logo é rotulada de gago ou então surdo-mudo. [...] O mundo muda toda hora, as pessoas estão com novos problemas, novos medos e novas infâncias. [...] Minha avó dizia que água e conselho só se dão a quem pede, mas acho que o currículo de fonoaudiologia precisava mudar um pouco e incluir muita psicologia e antropologia, além de procurar pessoas que tivessem solidariedade com o próximo [...] [grifos nossos] (Lia Mara)

A fonoaudiologia é uma profissão que exige muito estudo, porque cada paciente é um desafio e temos que estar atentos para não fazer uma receita para todos. Eu acho que ser cuidadoso e ético é da maior importância, e eu pautei trabalhar nestes princípios, o que não quer dizer trabalhar sem nenhuma falha [grifos nossos] (Sonia Veloso)

- Se a clínica acontece nas histórias construídas/ vividas entre terapeuta e paciente, as relações de supervisão entre profissionais devem ser cuidadas para que não atravessem essas histórias, transformando o colega em instrutor, o paciente em receptor de técnicas e "clínica" em treinamento.

Fazia parte deste grupo uma fonoaudióloga vinda do Rio de Janeiro, Maria Amália Jourdan Penedo. [...] Ela me convidou para trabalhar com ela num contrato verbal de supervisão, ou seja, eu atendia, passava o relatório dos pacientes para ela. [...] Funcionava como uma supervisão que eu não pedia, mas ela me dava. Eu aceitei e trabalhei durante muitos anos assim, até que, durante uma reunião clínica, a equipe questionou a situação e rompemos o combinado... [grifos nossos] (Leonora)

Rui Lobo foi pioneiro na realização dos exames auditivos eletrofisiológicos e isto foi muito importante, porque, além da redução do custo financeiro, não interrompia o trabalho fonoaudiológico e ainda diminuía a ansiedade da família. As famílias iam a cada seis meses a São Paulo, $e$ as avaliações (audiológicas e de linguagem) pareciam ser a solução para todos os problemas, desqualificando, de certa forma, o atendimento local em função de um atendimento idealizado no "sul maravilha", com repercussões no processo terapêutico lgrifos nossos] (Carmen Fernandes)

As narrativas são preciosas e reveladoras, ilustrando que a experiência de vida oferta sabedoria, está para além do factual, do conhecimento. Não é olhar o paciente como um objeto de estudo. É uma relação amorosa e verdadeira, com todos os seus riscos. É apreensão do sentido de que a clínica (cuidar) ocorre quando condições de confiança mútua, humildade e empatia possibilitam a comunhão de experiências e sentimentos entre terapeuta e paciente. Uma relação viva expressa pelo nome de solidariedade - abertura para o sentimento do outro, que reconhecemos pelo nosso destino comum - somos humanos:

[...] Entendo o problema dos outros, entro em empatia e quando alguém me procura faço tudo para tirar e não para botar pecado e culpa na história. [...] Não que eu ficasse vestindo a pele dele, mas eu compreendia a história de vida dele, porque também já tinha vivido uma história de dificuldade de comunicação, [...] precisava conversar com ele para conhecê-lo, porque senão iria só saber a garganta que ele tinha o o que me interessava era se ele podia confiar em mim. [...] Se tivesse conosco uma pessoa que pudesse ficar com ele depois, seria mais interessante. Mas não uma pessoa formal que ensinasse a técnica pela técnica, mas um companheiro. Está na hora de a gente mudar a cabeça e lembrar que precisamos de uma coisa chamada SO-LI-DA-RI-E-DA-DE. Acho que fonoaudiologia sem filosofia de vida não vai para lugar nenhum... Igrifo da entrevistada] (Lia Mara) 


\section{Considerações finais}

Não há, de fato, uma única história - são muitas as que vêm construindo a fonoaudiologia na cidade de Salvador. São muitas as faces que se apresentam na colheita das experiências vividas. Constituem percepções do passado ligado ao hoje, em continuidade, num processo histórico nunca concluído. Foram cinco entrevistas realizadas com profissionais que podemos denominar como precursoras da fonoaudiologia na capital baiana e que viajaram por vários tempos e espaços.

O narrar nos oferta um conhecimento tecido na experiência, que, além de iluminar a reflexão, nos coloca em pertencimento e nos concede conforto, trazendo nas histórias a dimensão do humano ou, melhor dizendo, daquilo que nos irmana.

A metodologia da história oral foi fundamental para o acesso às narrativas, por se constituir uma forma artesanal de comunicação que não visa a transmitir o acontecido, mas vai tecendo-o até atingir uma forma boa (Bosi, 1999).

Frente às sagas das narradoras, o desafio foi constituir outra história, partindo das nossas comunidades de destino: a fonoaudiologia e a dimensão humana, e a trama foi acontecendo pelo registro biográfico de cada uma delas em seus desafios singulares, nas suas presenças, na identidade factual dos caminhos da fonoaudiologia em Salvador, transbordando em sutilezas profundas, revelando a experiência na clínica a partir de um lugar de solidariedade.

As colaboradoras contaram sobre uma clínica da pessoa inteira, que não quer investigar, decifrar, interpretar, prescrever, corrigir, enquadrar. Nessa clínica as pessoas trabalham juntas, vivendo a experiência do encontro, buscando acompanhar e reconhecer o que de singular se organizou em cada pessoa: repertório linguístico, questões transgeracionais, constelação familiar para além do registro do vivido, do psíquico, aberto para o sentimento, para a reciprocidade e a aspiração de todo humano: estar incluído, fazer parte, ser cuidado.

\section{Referências}

AMADO, J.; FERREIRA, M. M. (Coord.). Usos \& abusos da história oral. Rio de Janeiro: Fundação Getúlio Vargas, 2001.

AZEVEDO, C. Regenerando a alma americana: os corpos da paz na América Latina. In: ENCONTRO DA ANPHLAC, 3., 1998, São Paulo. Anais eletrônicos... São Paulo, 1998. Disponível em: <http://anphlac.org/upload/anais/encontro3/ cecilia.pdf >. Acesso em: 12 jul. 2013.

AARÃO, P. C. L. et al. Histórico da fonoaudiologia: relato de alguns Estados brasileiros. Revista Médica de Minas Gerais, Belo Horizonte, v. 21, n. 2, p. 238-244, 2011.

\section{BERBERIAN, A. P. A. Normatização da língua} nacional: práticas fonoaudiológicas, 1920-1940. 1993. Dissertação (Mestrado em Distúrbios da Comunicação) - Pontifícia Universidade Católica de São Paulo, São Paulo, 1993.

BOSI, E. Memória e sociedade: lembranças de velhos. São Paulo: Cia da Letras, 1999.

BOSI, E. O tempo vivo da memória: ensaios de psicologia social. 2. ed. São Paulo: Ateliê, 2004. CARDOSO, C.; ABREU, T. T. A fonoaudiologia na Bahia: uma história recente. Revista Bahiana de Saúde Pública, Salvador, v. 28, n.1, p. 96-99, 2004.

DANESI, M. C.; MARTINEZ, Z. O. (Org.). Reconstrução histórica da fonoaudiologia no Rio Grande do Sul. Porto Alegre: IMEC, 2001.

DIDIER, M. S. L. Fonoaudiologia: sua história em Pernambuco. 2001. Dissertação (Mestrado em Fonoaudiologia) - Pontifícia Universidade Católica de São Paulo, São Paulo, 2001.

FIGUEREDO NETO, L. H. O início da prática fonoaudiológica na cidade de São Paulo: seus determinantes históricos e sociais. 1988. Dissertação (Mestrado em Distúrbio da Comunicação) - Pontifícia Universidade Católica de São Paulo, São Paulo, 1988.

KAUFFMAN, A. P. M. Fonoaudiologia: a profissão no Amazonas, dos pioneiros aos atuantes em 2006. 2006. Dissertação (Mestrado em Educação) Universidade Federal do Amazonas, Manaus. 2006. 
MEIHY, J. C. S. B. Manual de história oral. São Paulo: Loyola, 2005.

MEIHY, J. C. S. B. Augusto e Lea: um caso de (des) amor em tempos modernos. São Paulo: Contexto, 2006.

MONFREDINI, M. I. A gestão descentralizada e participativa da política de assistência social. 2003. Dissertação (Mestrado em Economia) Instituto de Economia da Universidade Estadual de Campinas, Campinas. 2003.

PEREIRA, A. C. Fonoaudiologia e história oral: uma narrativa sobre uma profissão construída por mulheres. 1999. Dissertação (Mestrado em Fonoaudiologia) - Pontifícia Universidade Católica de São Paulo, São Paulo, 1999.
PEREIRA, F. C. B. et al. Histórico da fonoaudiologia em Minas Gerais: impressão dos protagonistas. Revista Cefac, São Paulo, v. 14, n. 2, p. 313-326, 2012.

SAFRA, G. A po-ética na clínica contemporânea. São Paulo: Idéias\& Letras, 2004.

SILVEIRA, V. P. Da terapia da palavra a fonoaudiologia: práticas fonoaudiológicas na cidade do Rio de Janeiro de 1963 a 1981. 1996. Dissertação (Mestrado em Psicologia Social) Universidade do Estado do Rio de Janeiro, Rio de Janeiro, 1996.

SOARES, M. A. L. O oralismo como método pedagógico: contribuição ao estudo da história da educação do surdo no Brasil. 1996. Tese (Doutorado em Educação) - Universidade Estadual de Campinas, Campinas, 1996. 